\title{
Why do we need pharmacists in pharmacovigilance systems?
}

\author{
Hale Z. Toklu ${ }^{1}$ and Edward Mensah ${ }^{2}$
}

1. University of Florida Department of Pharmacology and Therapeutics

2. University of Illinois at Chicago School of Public Health

\begin{abstract}
Pharmacovigilance is the science and activity relating to the collection, detection, assessment, monitoring, and prevention of adverse effects with pharmaceutical products. Pharmacovigilance basically targets safety of medicine. Pharmacists have crucial role in health systems to maintain the rational and safe use of medicine for they are drug experts who are specifically trained in this field. Effective use of pharmacists' workforce will improve the outcome of the pharmacotherapy as well as decrease global health costs. Given their advanced training, pharmacists can utilize pharmacovigilance systems interfaced with electronic health records to monitor the performance of the drugs they fill and also identify adverse drug reactions earlier than non-pharmacists, thereby reducing high healthcare costs.

Keywords: pharmacovigilance; pharmacy; pharmacist; adverse drug reaction reporting; health system; rational use of medicine; pharmacotherapy

Correspondence: Dr. Hale Zerrin Toklu Department of Pharmacology and Therapeutics

College of Medicine, University of Florida, Gainesville, 32610 FL, USA +1 352 392-3395 haletoklu@yahoo.com

DOI: 10.5210/ojphi.v8i2.6802

Copyright @2016 the author(s)

This is an Open Access article. Authors own copyright of their articles appearing in the Online Journal of Public Health Informatics. Readers may copy articles without permission of the copyright owner(s), as long as the author and OJPHI are acknowledged in the copy and the copy is used for educational, not-for-profit purposes.
\end{abstract}

\section{Introduction}

Pharmacovigilance is the science and activity relating to the collection, detection, assessment, monitoring, and prevention of adverse effects with pharmaceutical products [1]. The word "pharmacovigilance" is derived from pharmakon (drug in Greek) and vigilare (keep an eye on/ monitor in Latin). Pharmacovigilance basically targets safety of medicines. Ultimately, pharmacovigilance is concerned with identifying the hazards associated with pharmaceutical products and with minimizing the risk of any harm that the patients can face $[1,2]$. In modern dataintensive era, pharmacovigilance information systems, operating like disease surveillance systems, 
can enhance the data collection, detection, assessment, monitoring and prevention of adverse effects.

Effective and safe pharmacological treatment process requires a team work of the patient and healthcare professionals. Pharmaceutical care includes considering these risks on a patientoriented basis by "identifying and solving (or avoiding)" drug therapy problems. Although the prescription is written by medical doctors in most countries, pharmacists and nurses have a crucial role in follow-up, since they can monitor and determine drug related problems; thus maintain safe use of medicines $[3,4]$.

Traditional pharmacy practice typically focuses on filling orders (prescription/ OTC), received from medical practitioners. In this model, pharmacists provide a service focused on the dispensing of medicine, rather than the provision of individualized care to the patient [5,6]. However, evidence suggests that patients often receive inadequate care using this traditional model [7-9]. On the other hand, pharmaceutical care is improved when pharmacists are actively involved in the treatment procedure by fostering the pharmacist-patient relationship and enhancing the value of the clinical outcome of the treatment $[10,11]$. The role of pharmacists in pharmacovigilance systems is amplified under Affordable Care Act or the current health care reform, because people who otherwise had no insurance, now qualify for insurance; and this could increase the demand for pharmacy services. More pharmacists will be required in delivering health education, including education on drug-drug interaction [12]. Also, in developing countries, pharmacists have a distinct role in in the health care system since many patients in prefer going to pharmacies for primary care. In such countries, pharmacists are more involved in the treatment process as well as the patient education [13]. Pharmacovigilance information systems, managed by pharmacists, can identify adverse drug reactions in developing countries where quality control of medicines is questionable.

The study by Akici et al (2007) showed that patients had insufficient knowledge about their prescribed drugs, although they had been using them for a while [14]. Another problem is ignorant use of herbs and herbal medicine [15]. Since many herbal products contain active ingredients that can interact with prescription medicines, WHO prepared a guideline on monitoring of herbal medicine in the pharmacovigilance systems [16]. In most countries, pharmacists go through an extensive education on medicinal plants which are used in traditional folk medicine, as well as the natural and synthetic medicines. Therefore, pharmacists already have the knowledge to detect safety signals of drugs of any origin [17].

Signal detection is important to identify the drug related adverse effects. However, the number of reports sent to national pharmacovigilance centers is also important as well as the quality of reports. The quality of reports is definitely superior when they are filled by health professionals who have pharmacology knowledge, i.e. pharmacists, doctors, nurses, physician assistants, dentists etc. It will be even better if it can be documented and retrieved from pharmacy information systems. 
According to the 2012 FIP Pharmacist Workforce Report, global sample reveals that, on average, $55 \%$ of pharmacists were found to work in community pharmacy environments, $18 \%$ in hospitals, $10 \%$ in industry, 5\% in research and academia and 5\% in regulation [18]. Roughly, 73\% of pharmacists work in hospital or pharmacy settings, where they can face events based on adverse drug reactions or other drug related problems. Their involvement in pharmacovigilance systems is crucial.

The changing role of the pharmacist from traditional 'drug dispenser' concept towards 'pharmaceutical care provider' expanded the role of pharmacists [13]. Pharmacists' role has become essential for the management of chronic diseases in patient-centered medical facilities where pharmacists are constituents of primary care [19]. Furthermore, the development of electronic information systems has been a milestone in identifying and intervening drug related problems such as dosage, adverse reactions, interactions, compliance or ineffectiveness [20]. Such decision support systems in electronic medical records can capture drug-drug interactions or identify other issues (e.g. contraindications) with prescriptions before they are filled. Thus, they improve safety. Such systems have also been shown to improve productivity of the providers as well as saving time [21]. Moreover, these databases provide a valuable source for costeffectiveness/ outcome analysis.

Because of the above mentioned reasons, pharmacists should be used more effectively in the system. They need to be directly involved in adverse drug reaction reporting using information systems to improve their performance. To reach this goal, regulatory bodies should make legislations to encourage pharmacists to be actively involved in the system. Besides their active participation, their assigned role should have a broader spectrum to obtain the maximum benefit based on their expertise. A sample organization scheme suggested for involving pharmacist in pharmacovigilance systems is given in Figure 1. This simple organizational scheme can be adapted in many countries effectively. The performance of this system can be enhanced by the use of information and communication technologies.

Since rational use of medicines requires that the patients receive "medicines appropriate to their clinical needs, in doses that meet their own individual requirements, for an adequate period of time, at the lowest cost to them and their community"; active/ more effective involvement of pharmacists in pharmacovigilance systems will improve the rational use of medicines.

\section{Conclusion}

Pharmacovigilance basically targets safety of medicine. Pharmacists play crucial roles in health systems in maintaining the rational and safe use of medicines since they are drug experts who are specifically trained in this field. Effective use of pharmacists' workforce will improve the outcome of the pharmacotherapy as well as decrease global health costs. 


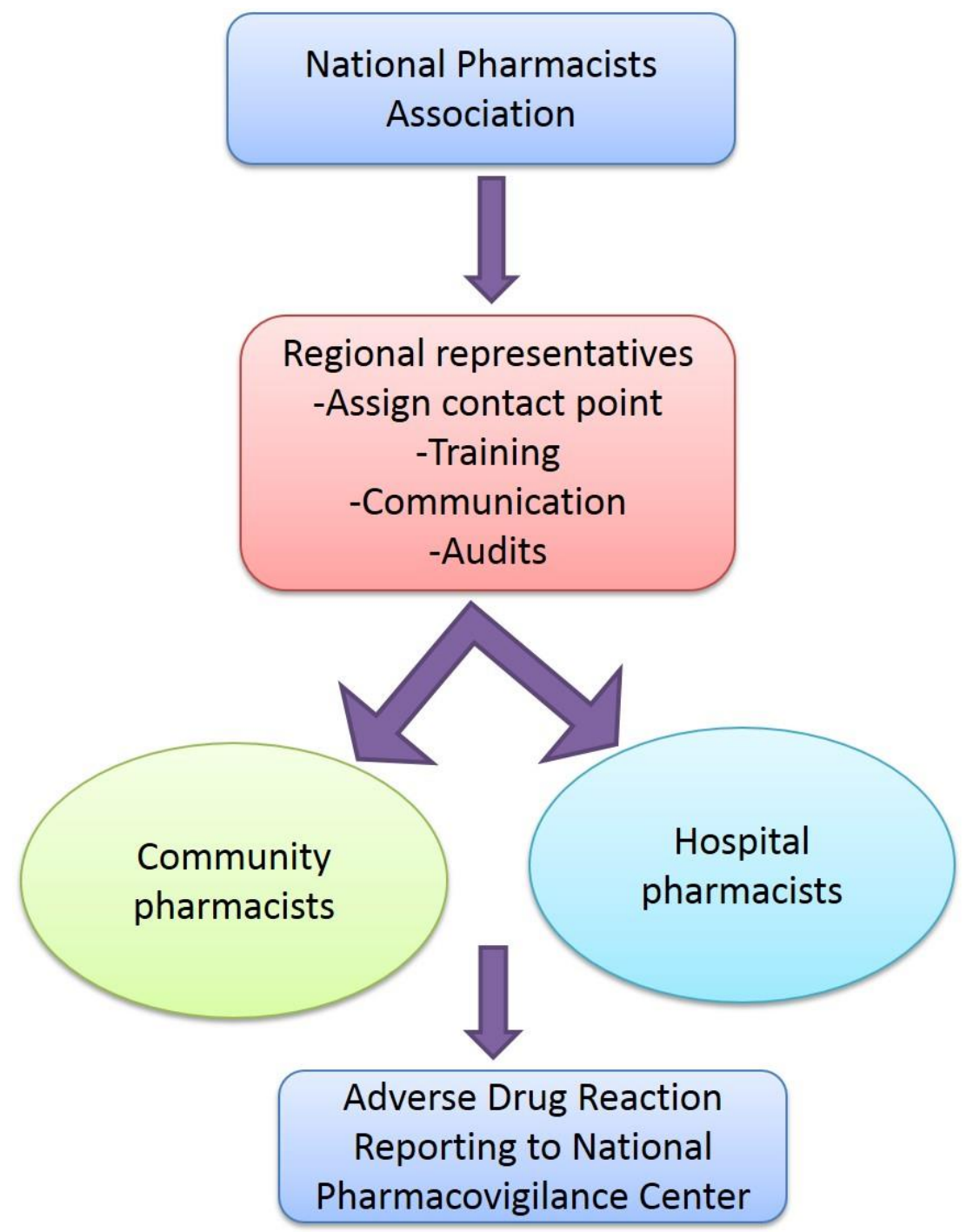

Fig. 1. A sample organizational scheme suggested for involving pharmacist role in the pharmacovigilance system. This simple organization scheme can be adapted in many countries effectively. 


\section{References}

1. World Health Organization. Safety monitoring of medicinal products: reporting system for the general public. Geneva: World Health Organization; 2012.

2. Mann R, Andrews E. Introduction. Pharmacovigilance. Mann R, Andrews E. (Eds.) John Wilesy \& Sons Ltd. West Sussex England. 2007, 2nd Ed. p3-11.

3. FIP (International Pharmaceutical Federation) Statement of Policy: the role of the pharmacist in pharmacovigilance, Brazil; 2006.

http://www.fip.org/www/uploads/database_file.php?id=273\&table_id (available at 04-052015).

4. Stephens MDB. Stephens' Detection of New Adverse Drug Reactions. Ed.Talbot J, Patrick W. West Sussex, John Wiley\&Sons Ltd, 2004. 5.Ed. p1-88.

5. Toklu HZ. Promoting evidence-based practice in pharmacies. Integrated Pharmacy Research and Practice 2015:4 127-131. https://www.dovepress.com/promoting-evidence-basedpractice-in-pharmacies-peer-reviewed-fulltext-article-IPRP\#

6. Toklu HZ. 2015. Pharmaceutical Education Vs. Pharmacy Practice: Do We Really Teach What They Need For Practicing? J Pharma Care Health Sys. S3, e001. http://www.omicsgroup.org/journals/pharmaceutical-education-vs-pharmacy-practice-dowe-really-teachwhat-they-need-for-practicing-2376-0419-1000e134.pdf.

doi:. http://dx.doi.org/10.4172/2376-0419.S3-e001

7. Toklu HZ, Soyalan M, Gultekin O, Ozpolat M, Aydin MD, et al. 2016. The knowledge and attitude of the healthcare professionals towards pharmacovigilance and adverse drug reaction reporting in Northern Cyprus. $J$ Pharmacovigil. 4, 193. http://www.esciencecentral.org/journals/the-knowledge-and-attitude-of-the-healthcareprofessionals-towards-pharmacovigilance-and-adverse-drug-reaction-reporting-in-northe2329-6887-1000193.pdf. http://dx.doi.org/10.4172/2329-6887.1000193

8. Gokcekus L, Toklu HZ, Demirdamar R, Gumusel B. 2012. Dispensing practice in the community pharmacies in the Turkish Republic of Northern Cyprus. Int J Clin Pharm. 34(2), 312-24. PubMed http://dx.doi.org/10.1007/s11096-011-9605-Z

9. Toklu HZ, Uysal MK. 2008. The knowledge and attitude of the Turkish community pharmacists toward pharmacovigilance in the Kadikoy district of Istanbul. Pharm World Sci. 30(5), 556-62. PubMed http://dx.doi.org/10.1007/s11096-008-9209-4

10. Toklu HZ, Demirdamar R. The evaluation of prescription dispensing scores of the pharmacy students before and after the problem-based "rational drug use" course: Results of the two years' experience. Marmara Pharmaceutical Journal 2013; 17: 175-180. http://edergi.marmara.edu.tr/marupj/article/view/5000010852/5000010871 
11. Toklu HZ. 2013. Problem based pharmacotherapy teaching for pharmacy students and $\begin{array}{lllll}\text { pharmacists. Curr Drug Deliv. } & \text { 10(1), } & \text { 67-70. }\end{array}$ http://dx.doi.org/10.2174/1567201811310010012

12. Amara S, Adamson RT, Lew I, Slonim A. 2014. Accountable care organizations: impact on pharmacy. Hosp Pharm. 49(3), 253-59. PubMed http://dx.doi.org/10.1310/hpj4903-253

13. Toklu HZ, Hussain A. 2013. The changing face of pharmacy practice and the need for a new model of pharmacy education. J Young Pharm. 5(2), 38-40. PubMed http://dx.doi.org/10.1016/j.jyp.2012.09.001

14. Akıcı A, Kalaca S, Ugurlu MU, Toklu HZ, Iskender E, et al. 2004. Patient knowledge about drugs prescribed at primary healthcare facilities. Pharmacoepidemiol Drug Saf. 13(12), 87176. PubMed http://dx.doi.org/10.1002/pds.1020

15. Ozkum D, Ak1 O. 2013. Toklu HZ. Herbal medicine use among diabetes mellitus patients in Northern Cyprus. J Med Plants Res. 7(22), 1652-64.

16. WHO Guidelines on safety monitoring of herbal medicines in pharmacovigilance systems. Geneva: World Health Organization; 2004.

17. Toklu HZ. 2016. Pharmacovigilance of Herbal Medicine: Herbavigilance. Adv Pharmacoepidemiol Drug Saf 5:208. doi: 10.4172/2167-1052.1000208

18. 2012 FIP Global Pharmacy Workforce Report. Ed. Diane Gal. Hague, Netherlands, 2012. http://www.fip.org/files/members/library/FIP_workforce_Report_2012.pdf

19. Schumacher C. Pharmacist Involvement in a Patient-Centered Medical Home. PPMI Case Study. Available at: http://www.ashpmedia.org/pai/docs/casestudy-Midwestern.pdf [accessed Jun 18th 2016]

20. Smith M, Giuliano MR, Starkowski MP. 2011. In Connecticut: improving patient medication management in primary care. Health Aff (Millwood). 30(4), 646-54. doi:. PubMed http://dx.doi.org/10.1377/hlthaff.2011.0002

21. Schoenhaus R, Lustig A, Rivas S, Monrreal V, Jr, Westrich KD, et al. 2016. Using an Electronic Medication Refill System to Improve Provider Productivity in an Accountable Care Setting. J Manag Care Spec Pharm. 22(3), 204-08. PubMed http://dx.doi.org/10.18553/jmcp.2016.22.3.204 